


\section{Insect Enemies and Diseases of the Tomato}

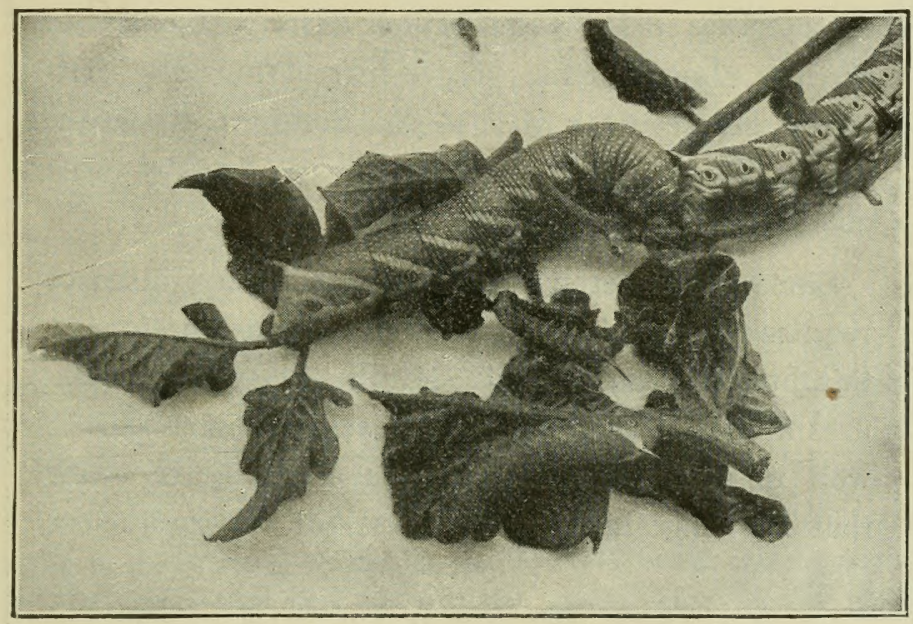

UNITED STATES DEPARTMENT OF AGRICULTURE DEPARTMENT CIRCULAR 40

Contribution from the States Relations Service

(Office of Extension Work South)

A. C. TRUE, Director 
LUB MEMBERs need and have asked for sim4 ple, reliable instructions for controlling the insect pests and diseases which come to the plants in their club gardens. These instructions are written to aid the club girls of the Southern States in preventing or controlling the damage done by these enemies of their gardens.

Since the different types of insects and diseases require widely varying treatment, the instructions in this bulletin are given in detail. Preventive measures are most important, and each club girl will do well to study the instructions carefully in order that she may intelligently care for her tenth-acre plot.

Further information on diseases and insects can be secured from Farmers' Bulletin 856, Control of Diseases and Insect Enemies of the Home Vegetable Garden. 


\section{SB.608 T75U 47}

\section{Insect Enemies and Diseases of the Tomato}

To Canning Club Members:

You have already received Circular A-97-in which you were told how to select and prepare your tenth acre, how to make hotbeds, cold frames, and seed boxes, and how to transplant, fertilize, and cultivate tomatoes.

You may, during the season, have trouble with tomato diseases. At the same time that you try to prevent diseases, it will be necessary to look out for insect pests which may do great harm. Then, too, you can fight insect pests and tomato diseases at the same time. You must understand that you can much more easily and cheaply take steps to keep your plants healthy than you can cure them after they become diseased. In fact, if the soil in which you plant your vegetables is infected with some of these diseases, you can not hope to have healthy plants. It is too late to apply remedies after you see the trouble. You have already been told not to use soil for hotbeds or cold frames in which diseased tomatoes grew last year.

\section{INSECTS INJURIOUS TO THE TOMATO. ${ }^{1}$}

From the time tomatoes are set in the gardens until the fruit has ripened, they are subject to attack by injurious insects. The principal of these are cutworms, flea-beetles, blister beetles, stalk-borers, plant-lice, red spider, and white fly.

\section{CUTWORMS}

Among insects most to be feared and of those which attack the plants when they are first set out are cutworms (fig. 1) of various kinds.

These smooth, plump, gray or brownish caterpillars conceal themselves during the day underground near the plants attacked, emerging toward evening to feed. The usual method of attack is to cut off the plant near the surface of the ground. They cut off and destroy more than they eat and resetting is frequently necessary. One cutworm can destroy many more plants in a single night than it can devour.

Control.-Cutworms are not difficult to control, the best method being the use of poisoned bait or poisoned bran mash. The following formula is used:

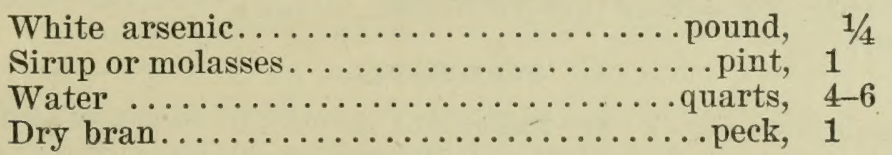

\footnotetext{
${ }^{1}$ Prepared by F. H. Chittenden, Entomologist in Charge, Truck Crop Insect Investigations, Bureau of Entomology.
} 
Thoroughly mix the arsenic in a peck of dry bran. Stir into 4 to 6 quarts of water a pint of cheap sirup or molasses. After this has been made up into a mash, let it stand for several hours to allow the bran to take up the arsenic.

Scatter the mash thinly along the rows or about the bases of the plants to be protected as soon as the cutworms appear. It is better to make the application well toward evening, or at dusk, since

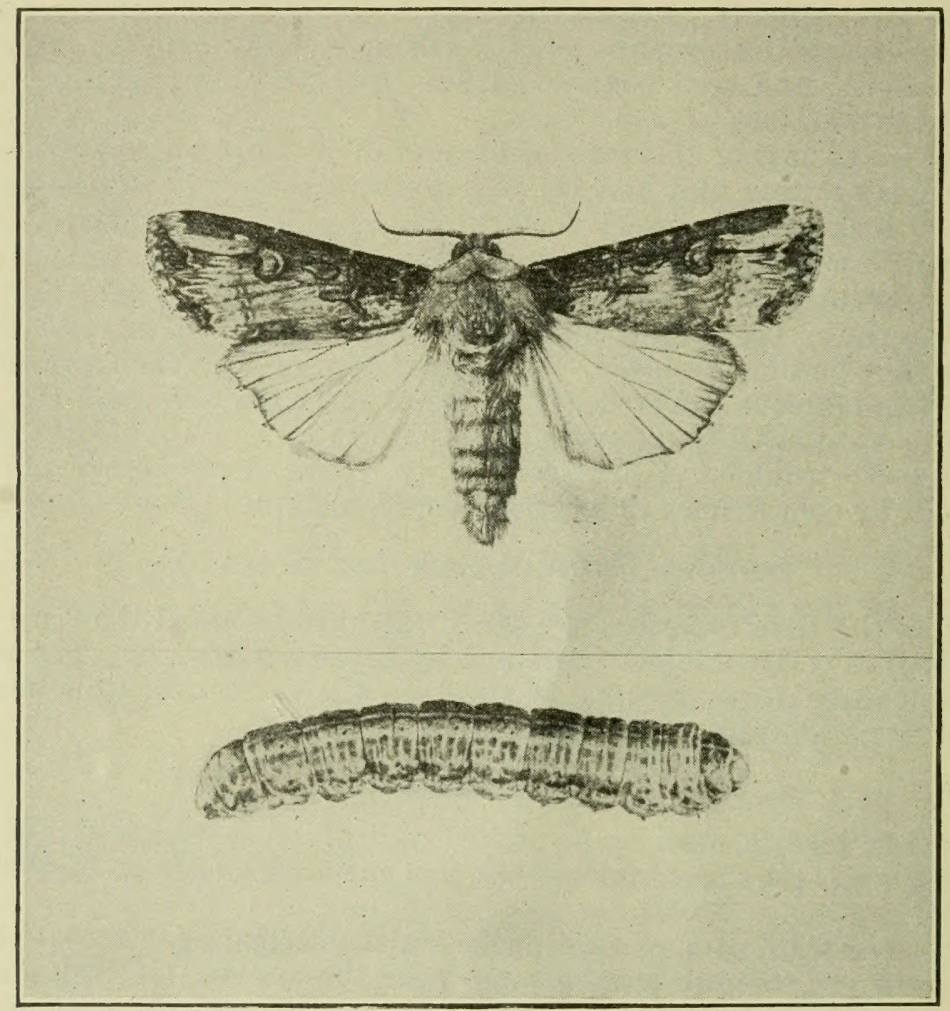

FIG. 1.-Greasy cutworm below; moth above-somewhat enlarged. This moth is distinguished from similar ones by a mark on each - upper wing resembling the capital Greek letter upsilon.

cutworms feed at night or on dull, cloudy days, and fresh bait is more attractive. If cutworms reappear, repeat two or three times at short intervals of 3 or 4 days to a week.

Caution.-Keep the younger children, live stock, and chickens away from the bait, as it is poisonous. With proper care there is no dạnger.

\section{FLEA-BEETLES.}

Flea-beetles (fig. 2) are important enemies of tomatoes, attacking the plants soon after they are set and again later in the season. They riddle the leaves of young and tender plants with small holes, causing the leaves to die and weakening the plants. They derive 
their name from the fact that they take long, quick leaps like a flea, being also of about the size of these little insects and dark in color.

Control.-Spray the plants thoroughly, both on the upper and under sides of leaves, with Bordeaux mixture, as this acts as a repellent, literally keeping them away. Wild plants of the potato kind such as ground cherry plants, should be pulled and destroyed throughout the season so as to leave no breeding places for the flea-beetles. Injury can also be prevented by dipping the young

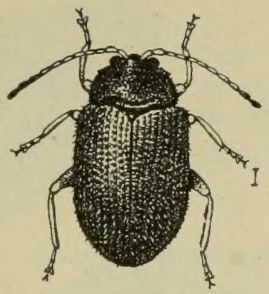

FIG. 2.-Potato fleabeetle. Size shown by line at right. plants before setting, in a solution of arsenate of lead at the rate of 10 level teaspoonfuls to a gallon of water.

\section{BLISTER BEETLES.}

Blister beetles (fig. 3) are common farm pests and are very destructive to tomatoes and other vegetables. They are ravenous feeders and travel frequently in lines, or following the rows of
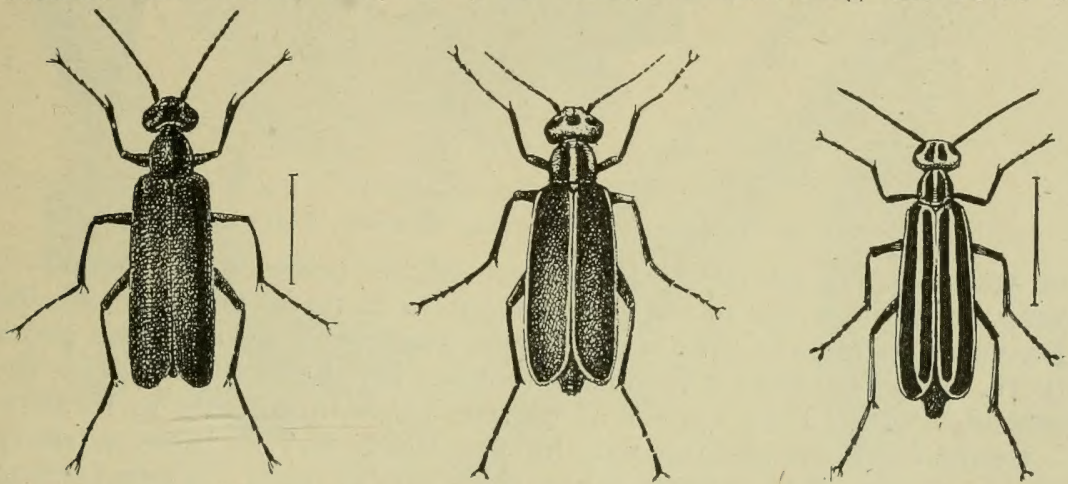

FIG. 3.-Adult blister beetles, enlarged: Left, black blister beetle; middle, margined blister beetle; right, striped blister beetle.

plants, eating everything in their path, chewing up apparently more than they need for food. They are large beetles, slender in form, somewhat soft-bodied, and variously colored. Some kinds are black, some yellow with black stripes, some are gray, and others are gray, spotted with black. Blister beetles are particularly abundant in the Southwest, but occur practically everywhere. They usually begin to appear in early midsummer after the plants have made about onethird growth, and some kinds continue until late in the season.

Control.-A spray of arsenate of lead, 10 level teaspoonfuls of powder to 1 gallon of water, applied at the very outset of attack, is the best remedy. Hand-picking is somewhat dangerous, as the blister beetles are likely to form blisters on delicate skin. They are extremely active, dropping quickly from the foliage. On this account they are easily knocked into large pans containing a little water and a few drops of kerosene which kills every beetle it touches. This remedy is especially valuable on well-grown plants.

\section{TOMATO HORNWORMS.}

The tomato hornworms (fig. 4) or tobacco worms, are large, green caterpillars, the young of large gray humming-bird moths with rows 


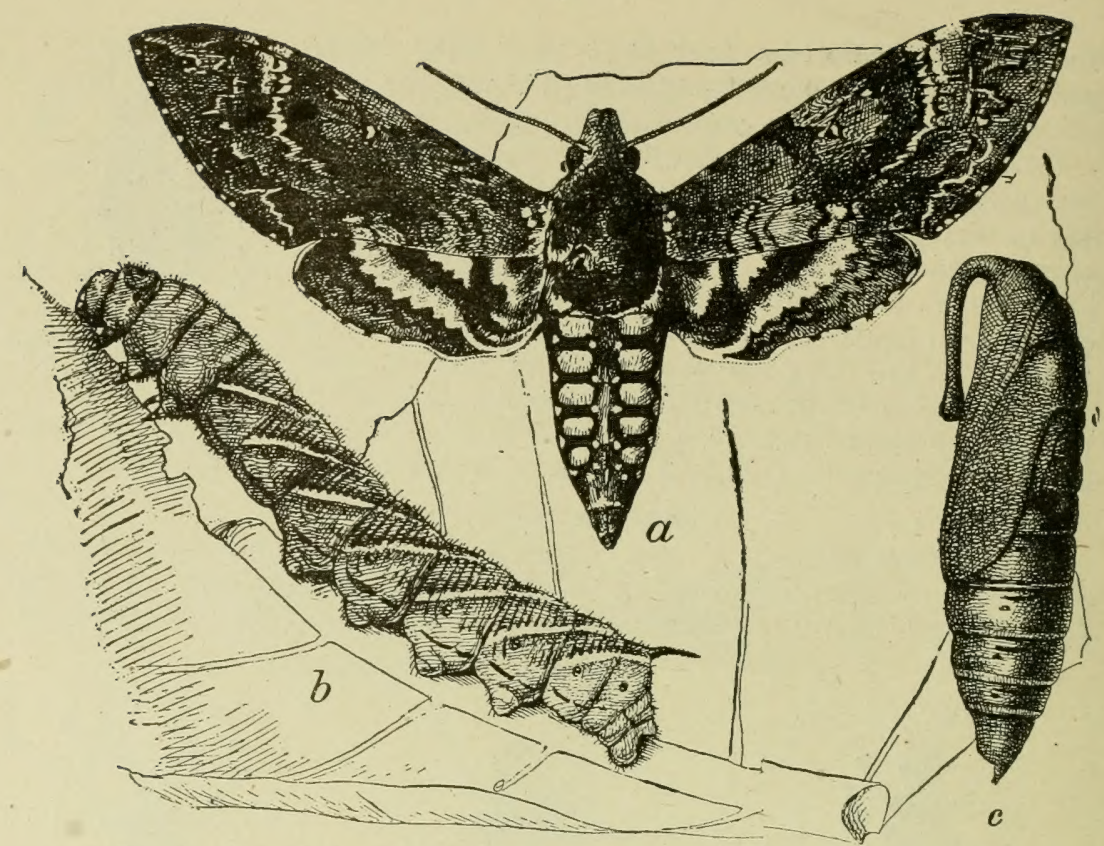

FIG. 4.-One of the tomato hornworms: $a$, moth; $b$, larva ; $c$, pupa.

of yellow spots on the body. These moths produce two broods a year, and when the caterpillars begin to mature they cut all the leaves from tomato plants, and even gnaw and destroy the green fruit. Growers should be on the lookout for the first as well as the second brood. They appear at various times, according to locality.

Control.-Hand-picking can be practiced, but it takes a sharp eye to detect these worms when they are at rest. When feerling they are more easily seen and

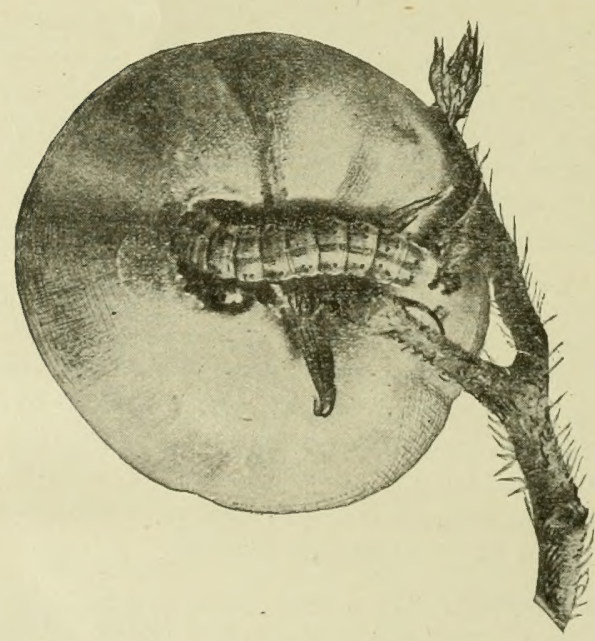

Fig. 5.-Characteristic work of the tomato fruitworm. can be destroyed readily. A single spraying with arsenate of lead at the rate of $\mathrm{T} / 4$ pound to 3 gallons of water, will destroy them when properly applied. Thos e which eat the poison first will be found dead the following day, the remainder on the second and third day.

\section{TOMATO FRUITWORM.}

The tomato fruitworm (fig. 5 ) is the same insect as the bollworm of cotton and the corn earworm, and is the cause of much trouble to tomato growers because of its eating into the ripening fruit and destroying its market value. 
Control.-Arsenate of lead, I/4 pound to 3 gallons of water, sprayed on the leaves two or three times will keep the insect partly under control. As long as sweet corn is growing nearby it attracts the worms, and thus protects the tomatoes. Hand-picking is difficult for large gardens and must be practiced almost daily for small patches.

\section{STALK-BORER.}

Tomato plants may sometimes be noticed to wilt down almost over night, without apparent cause. Examination of such plants often reveals near one of the joints of the stalk a small, round hole, the entrance to a burrow occupied by an insect. On splitting the stalk (fig. 6) a slender striped caterpillar will be disclosed. This pest is known as the stalk-borer.

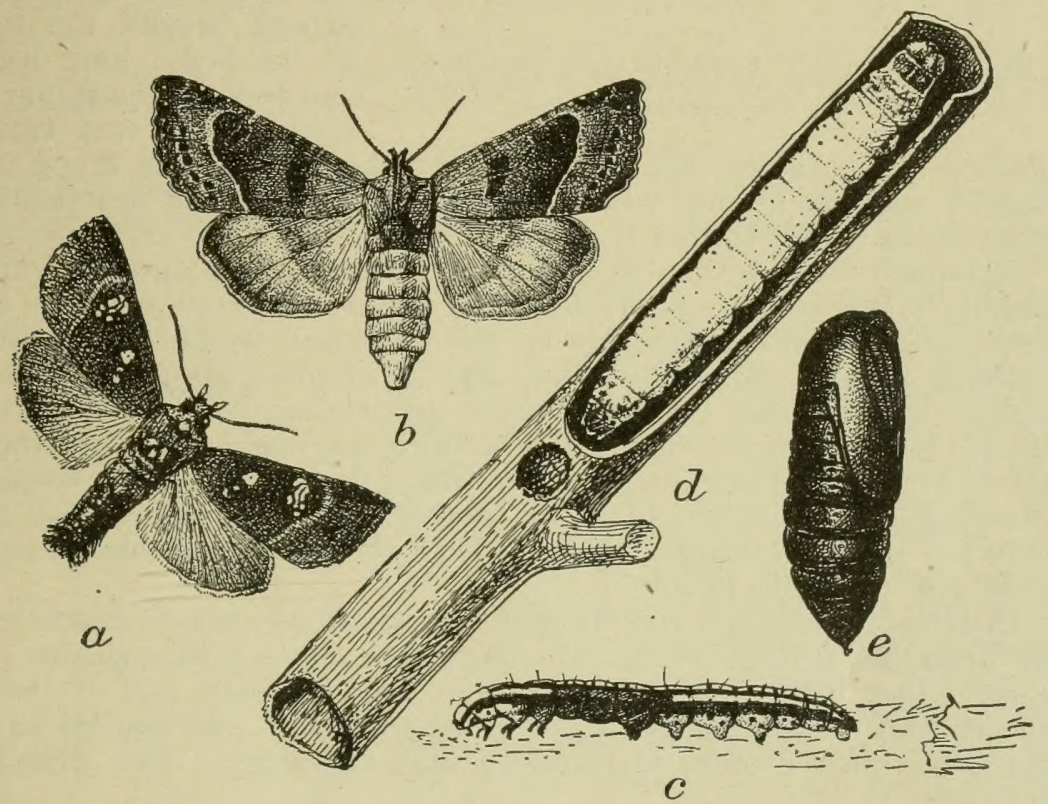

Fig, 6.-The common stalk-borer: $a$, typical form of moth (male); $b$, nitela form (female) ; $c$, young larva; $d$, mature larva in injured stalk; $e$, pupa. All somewhat enlarged.

Control.-The stalk-borer usually breeds in the stems of ragweed and burdock and when these are cut or hoed out during the grow. ing season it deserts them, often coming upon tomato and other crops planted for human use. This points out the most effective method of control-prevention by clean culture. The weeds mentioned should not be allowed to grow in or near the tomato garden and should be kept down during the season. When borers are found they should be killed, as they may injure a number of plants before reaching full growth. Spraying with arsenicals for other insects which may be present may also protect plants somewhat against this pest, but it is not a specific remedy.

\section{PLANT-LICE。}

Two forms of plant-lice or aphides (fig. 7), known respectively as the potato aphis and the spinach aphis have in recent years become 


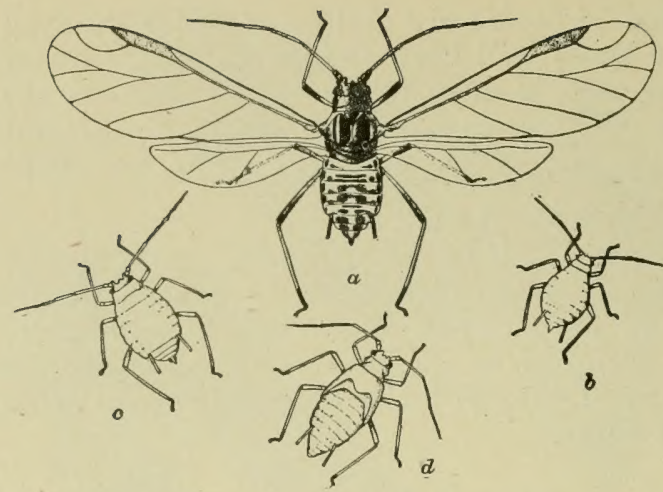

FIG. 7.-An aphid: $a$, winged adult aphis; $b$, young nymph: $c$, older nymph; $d$, last stage of nymph, or pupa. Greatly enlarged. extremely destructive to tomatoes in the northwestern part of the United States. The potato aphis, often called the tomato aphis, is one of our largest forms of plant-lice. It is of variable color, usually of a pinkish tinge, although some individuals are green. It measures about $1 / 8$ of an inch and has honey tubes which extend beyond the tip of the body, long legs and feelers. The spinach aphis, while very trou-

blesome on potatoes and tomatoes, attacks many other crops, is smaller, and has a much wider distribution, being found practically everywhere in the United States.

Aphides subsist by sucking the vital juices of the plants, and are nsually found on the underside of the leaves, where they gather in large colonies, and frequently on the buds and tips of the young growing plants. Sometimes they appear to cover all parts of the plant. Through the two honey tubes protruding from the back of the plant-lice, a sweet, honey-like liquid is secreted. Ants are very fond of this liquid and often keep the plant-lice as their "milk cows," carrying them from one plant to another. It is, therefore, well to look for ants and destroy their nests in the vicinity of plants corered with plant-lice or aphides.

Control.-These and similar pests can positively not be destroyed by arsenical poison. What are known as contact insecticides or those which kill by touching the body, are the best, and of these 40 per cent nicotine sulphate combined with soap and applied as a spray has proved more satisfactory than any other. The :ormula follows :

Nicotine sulphate (40 per cent) .......teaspoonful, 1

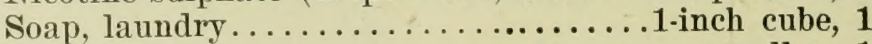

Water .................................. 1

Directions are also furnished on the package.

Dissolve the soap in the water, add the nicotine sulphate, and apply as a fine mist-like spray to the lower sides of the leaves, being careful to hit or cover all of the "lice." Use an under spray.

\section{RED SPIDER.}

Tomatoes, and nearly all vegetables, are subject to attack by the red spider (fig. 8). This pest is not a true spider, but a reddish mite of almost microscopic size. It is well distributed throughout the country, and is particularly troublesome on tomatoes, cucumbers, and beans. This mite injures plants by sucking the juices, and when plants are neglected they become so weakened by loss of sap that the crop is greatly reduced. In cases of severe attack, millions of red spiders gather on the underside of the foliage, and the 
webs which the insect spins from leaf to leaf can be easily seen, with the mites passing rapidly over them in swarms. Frequently the plants look as though scorched by fire. More often than not the red spiders are present without the grower's knowing it, "lust" being blamed for the injury.

Control.-A spray made with 1 pound of laundry soap in 8 gallons of water, applied frequently to the underside of the leaves, will hold the pest in check. Flowers of sulphur mixed with water at the rate of 1 ounce to 1 gallon, sprayed over infested plants, is a good remedy. Unless the spraying is begun when the insects are first noticed and repeated as often as needed, red spiders are almost certain to do great harm to delicate plants, since if the plants become thoroughly infested they seldom survive and the crop is lost.

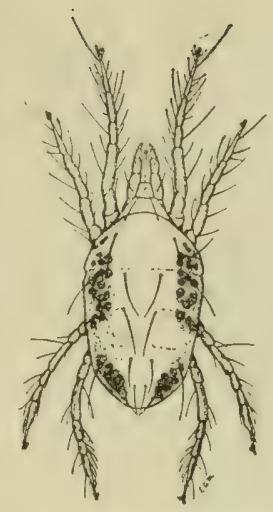

FIG. 8.-Red spider, highly magnified.

WHITE FLY.

White flies (fig. 9) frequently cause injury to the tomato, both in the garden and greenhouse. They are tiny white moth-like insects,
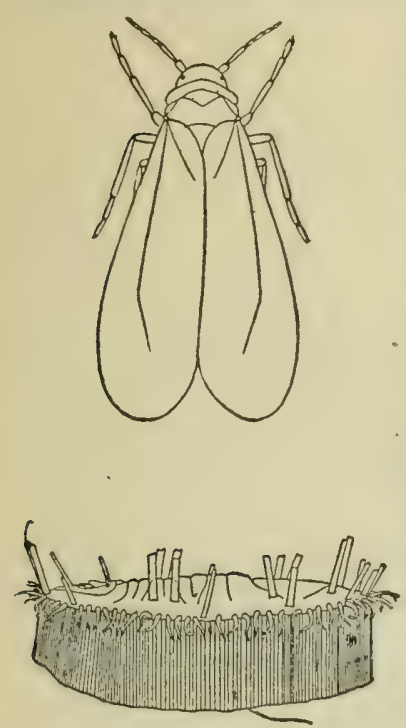

FIG. 9.-White fly - adult; winged form above, "larva" or scalelike form be $1 / 16$ of an inch long, and usually attract attention through their habit of flying into the air when the plant on which they are feeding is disturbed. Examination of the plants will show numerous small scale-like whitish objects attached to the underside of the leaf-the larvae or young of the white fly. The injury caused by this pest, which at times becomes so numerous as to cover nearly the entire lower surface of the foliage, results from the continual drain on the sap of the plant on which the insect subsists. The leaves first assume a lighter color, becoming yellowed as attack progresses, until death of the tissues takes place, and the leaf becomes dry. In addition, a small amount of a sweet liquid called honeydew is secreted by the insects, which, dropping on the foliage beneath, acts as a medium for the growth of molds and fungi.

Control.-Whale-oil (fish-oil) soap at the rate of 1 pound to 8 gallons of water, sprayed thoroughly on the underside of the leaves, will destroy nearly all of the larvae. A solution of laundry soap at the same rate is nearly as effective. It must not be forgotten that these insecticides must be brought into contact with the bodies of the insects to kill them.

\section{TOMATO DISEASES. ${ }^{7}$}

The principal tomato diseases in the South are tomato wilt, early blight, root-knot, sclerotium blight, southern tomato blight, leaf

\footnotetext{
${ }^{1}$ Prepared by W. A. Orton, Pathologist in charge, Cotton, Truck, and Forage Crop Disease Investigations, Bureau of Plant Industry.
} 
spot, downy mildew, blossom end rot, and anthracnose, or ripe rot. Not all of these are likely to occur in any one field, and even those that usually do appear can often be prevented or reduced by using a little care in selecting the field and in controlling conditions in the seed bed.

\section{SELECTION OF THE GROUND.}

Much of the land around farm buildings in the South is infected with diseases like root-knot and wilt. Therefore your first care should be to make a clean start by selecting land you believe to be free from disease. As a general rule, do not plant tomatoes in the same soil oftenel than once in three years. Find out what crop was on the land last year and look out for diseases of other plants which may also infect tomatoes. One of the most serjous of these is root-knot, which occurs in sandy soils. You can tell it by the knots or galls on the roots. Do not plant your tomatoes where any crop was infected with root-knot last year.

CARE OF THE SEEDBED.

A number of diseases appearing on tomatoes in the field originate from the seedbed. They are introduced in the field at the time of transplanting. It is therefore especially inportant to grow the seedlings in as healthy condition as possible. The following pre cautions should be observed.

1. Thenerer possible make the seedbed on new soil or at least on soil which did not grow a cropl of tontatoes the previous year.

2. Avoid the use of fresh manure.

3. Do not crowd the plants in the seedbed.

4. Spray the plants in the seedbed at least once, with a weak (2:2:50) solution of Bordeaux.

5. Remove and burn all diseased plants.

6. Avoid the use of plants for transplanting which show a spotting of the leaves, and particularly those which have knotted or swollen roots.

DAMPING OFF.

Have you had trouble with your tomato seedlings in the seedbed? If the roumg plants shrivel at the soil line, fall over and die, they are affected by the disease called "Damping off" (fig. 10), caused by

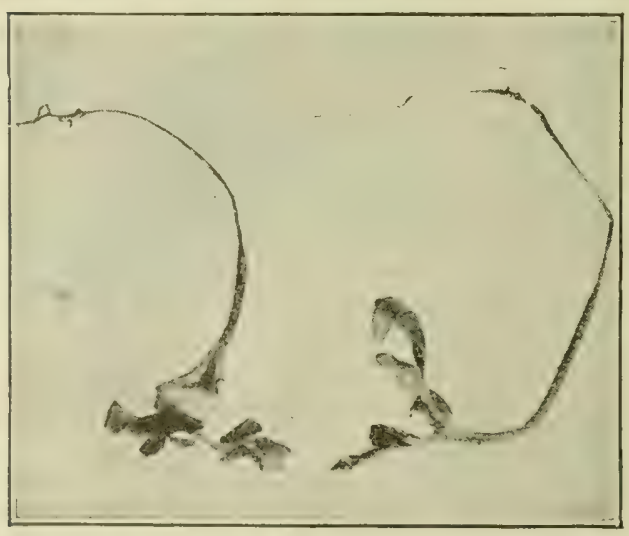

FIG. 10.-Damping off of tomato seedlings. Stems shriveling and dying at the soil. line. molds in the soil and made worse by overwatering and lack of ventilation.

It will help to prevent this if you will pour boiling water over the soil in the boxes or frames, using 5 gallons per cubic foot, 2 to 3 quarts for an S-inch pot. Do this a day or two before planting. While the plants are in the seedbed, give them plenty of air and sunlight, stir the surface. of the soil slightly, and do not overwater or let them dry out. 


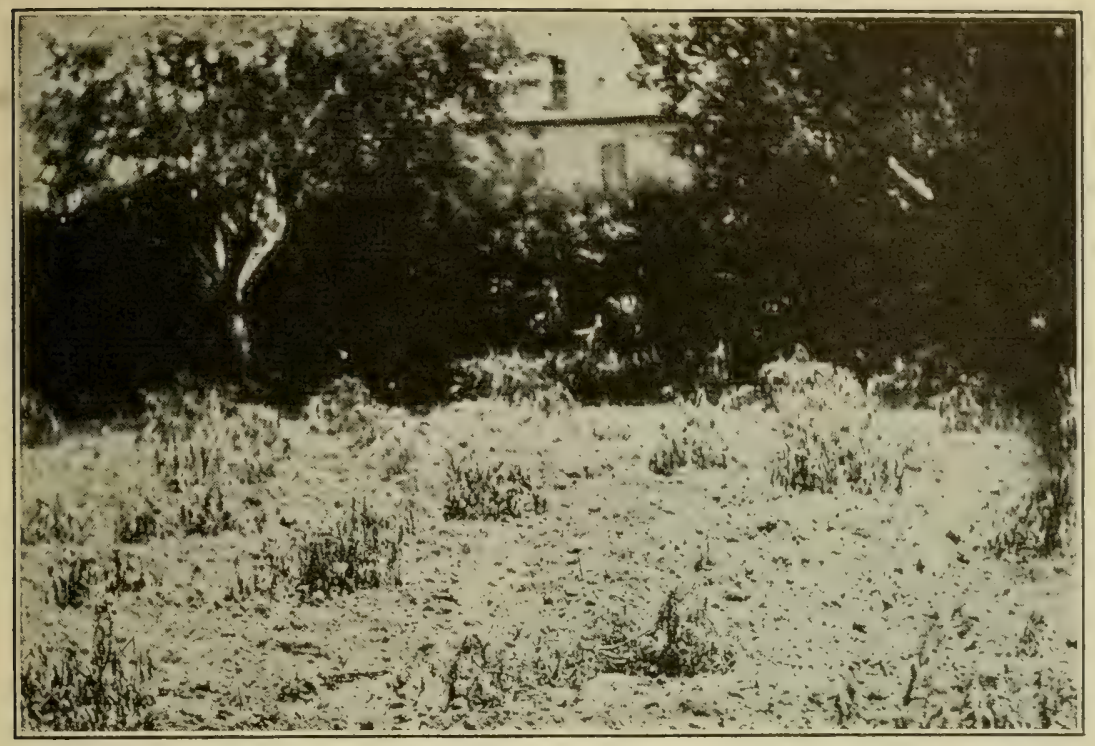

FIG. 11,-Tomato wilt.

TOMATO WILT.

Tomato wilt (fig. 11) is caused by a mold-like fungus that lives in the soil and infects the plants through their roots. Wilting, yellowing of the leaves, and a slow death of the plants are the results of attack.

Control.-Use either land that is free from wilt or wilt-resistant varieties.

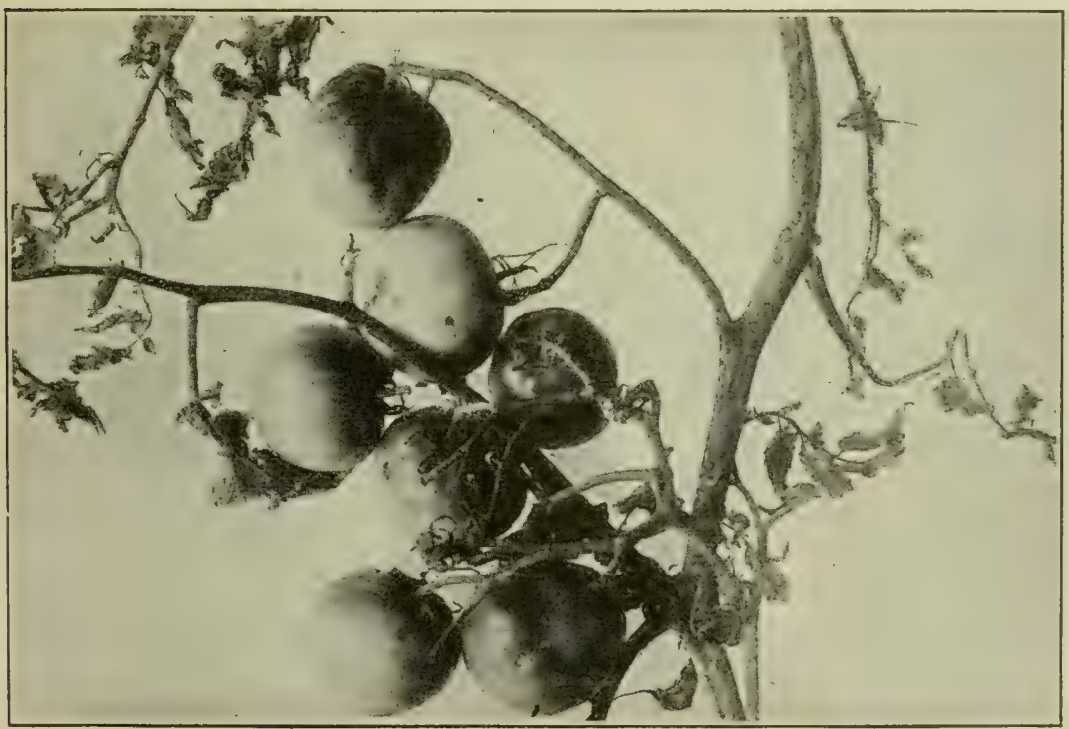

FIg. 12,-Early blight of tomato, showing infection of leaves, stems, and fruit. Leaves covered with brown spot shrivel and die. 


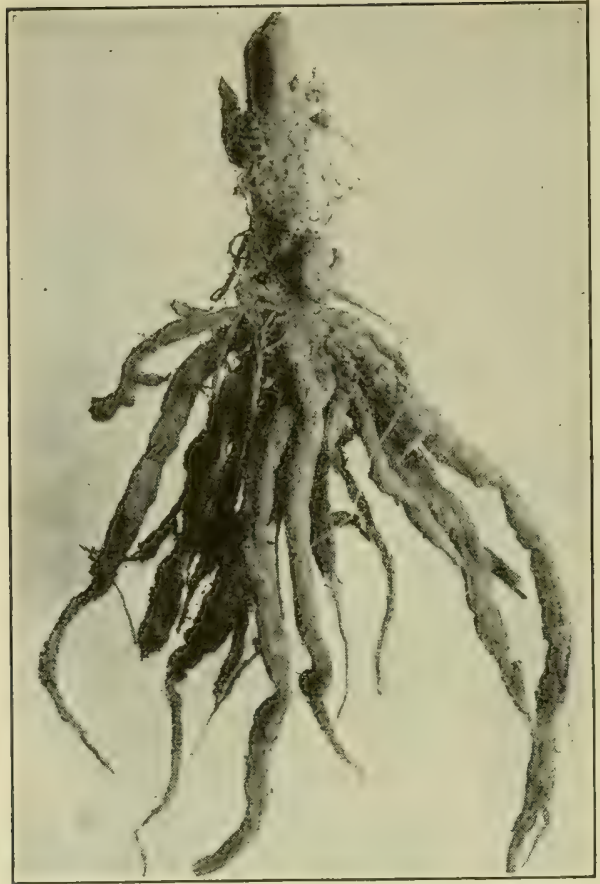

FIG. 13.-Root knot of tomato. Small knots at base of stem; large thickened roots below.

are not attacked by the root knot, such as Iron cowpeas, corn, oats, velvet beans, and peanuts.

\section{SCLEROTIUM BLIGHT.}

Sclerotium blight (fig. 14) is caused by a fungus which attacks the plant at or near the surface of the ground and causes rotting of the root. It also attacks branches that lie upon the ground. On the affected parts grows a white mold covered by small white to reddishbrown bodies about the size of mustard seed. These are dense masses of -fungus called sclerotia from which the disease takes its name.

Control. - Prune and stake the plants to aerate and dry the surface soil and keep the branches off the ground.
EARLY BLIGHT.

Early blight (fig. 12) affects leaves, stems, and fruit. On the fruit it is called nail head rust. It is often developed in the seedbed and carried to the field on the plants.

Control.--Spray the plants in the seedbed with weak (2:2:50) Bordeaux mixture and set in the field only plants that are free from the disease. If after these precautions the disease develops in the field, spray as directed under Spraying 'Tomatoes.

\section{ROOT KNOT.}

Root knot (fig. 13) is caused by very tiny worms called nematodes, which attack cotton, cowpeas, melons, okr'a, beets, tomatoes, potatoes, and other plants. Soil can be freed from this pest only by planting it for two or three years in crops which

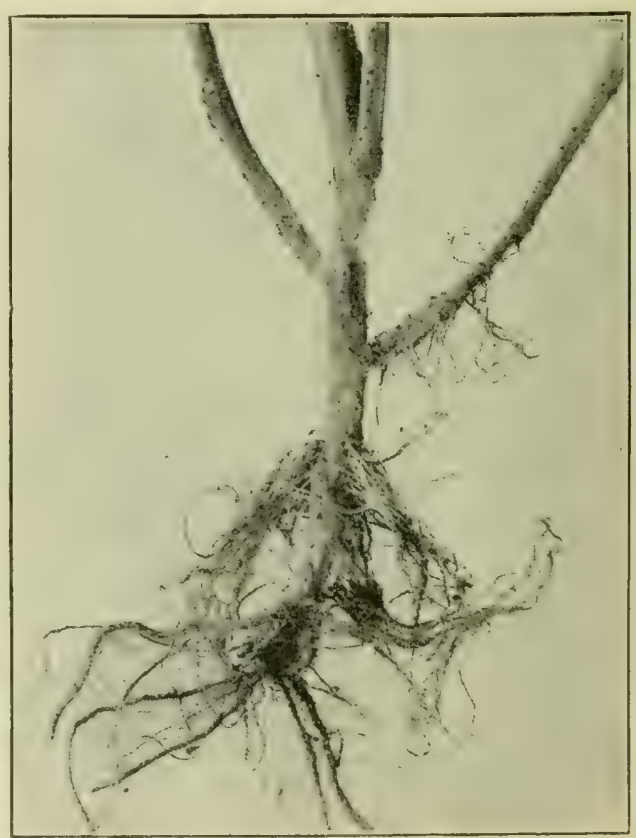

Fic 14-Sclerotium blight of tomato. Infection and decay of stem at surface of ground. 
SOUTHERN TOMATO BLIGHT.

Southern tomato blight is somewhat similar to tomato wilt, but it kills the plant more quickly. In fact the whole crop may be destroyed within a few days. In both these diseases there is a darkening of the stem just under the bark, but in the case of tomato wilt this area is dark-brown to black while in southern tomato blight it is yellow.

The $d$ is ease is caused by a bacter i m which is spread by insects.

Control.-Burn in. fected plants and spray the others with Bordeaux mixture containing $1 / 2$ per cent of lead arsenate.

\section{LEAF SPOT.}

Leaf spot (fig. 15) is a fungus disease, causing small, circular spots with light

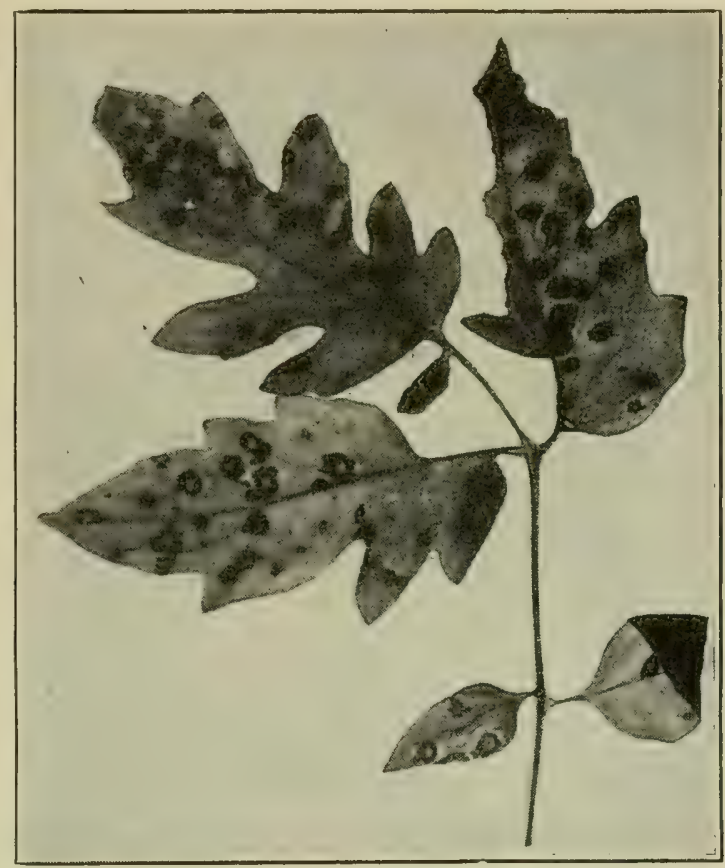

FIG. 15.-Leaf spot of tomato. Note size, shape, and color of spots.

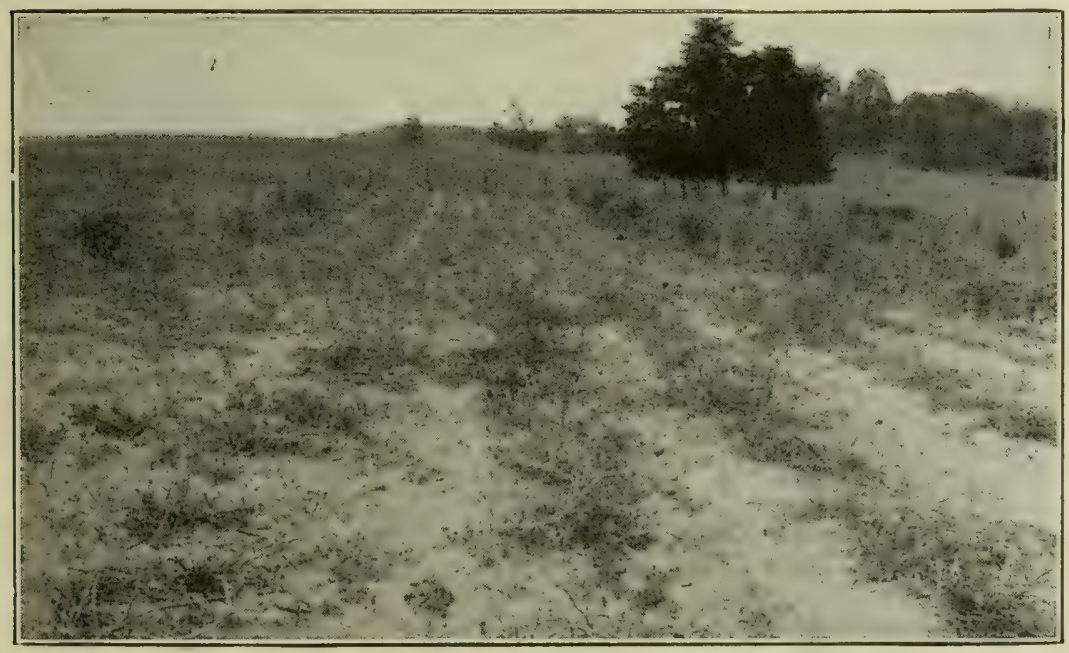

Fig, 16. Field of tomatoes ruined by leaf spot. Stems bare except at the tips. 


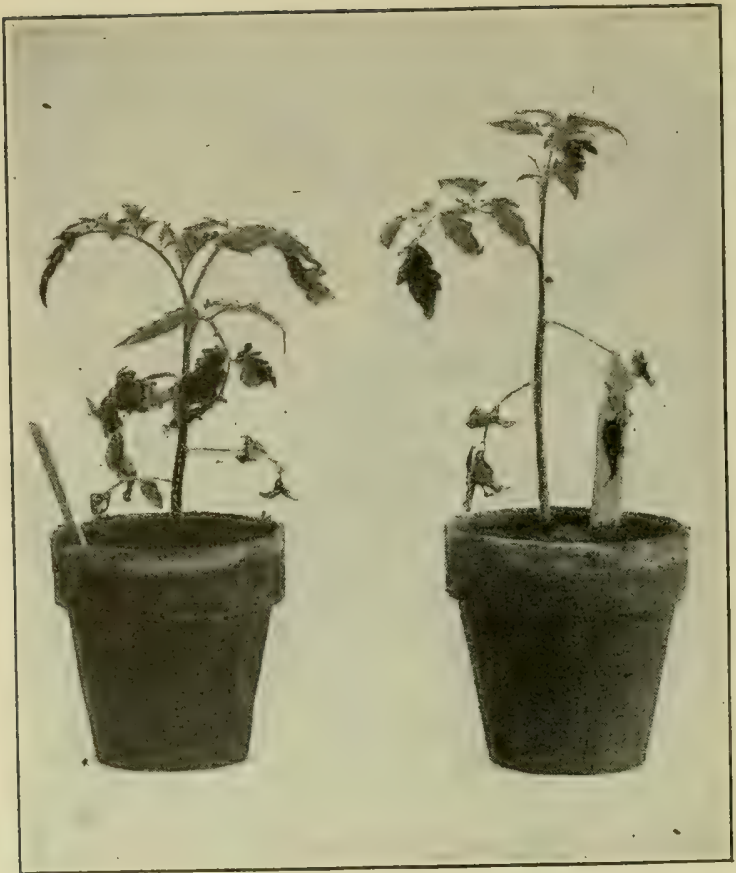

FIG. 17.-Downy miliew of tomatoes, showing infection of the lower leaves. centers and $\mathrm{d}$ a $\mathrm{rk}$ borders, on the leaves, and gray spots on the stems. In f e c te d leaves dry up and fall off, leaving the stems bare (fig. 16) except at the tips where a few small leaves continue to grow.

Control.-Burn all plants affected by the disease in the seedbed, and transplant only healthy plants to the field. If leaf spot a t a cks the plant in the field and is unusually destructive, spray twice at intervals of a week and three times at in. tervals of ten days with Bordeaux mix. ture.

DOWNY MLDEW.

Downy $\mathrm{mildew}$ is caused by a f u $\mathrm{n}$ g us which spreads only in cool, m o is t weather. Figure 17 shows an early stage of the disease on the lower leaves. It first appear's as irregular, blackened areas, which result in the death of the parts. Often the disease kills the plants so rapidly that it gives them a frost-stricken appearance. It also affects the fruit (figs. 18 and 19), first as a water-soaked area near the stem end, and later as a blackened area within the fruit. The most effective remedy is the Bordeaux

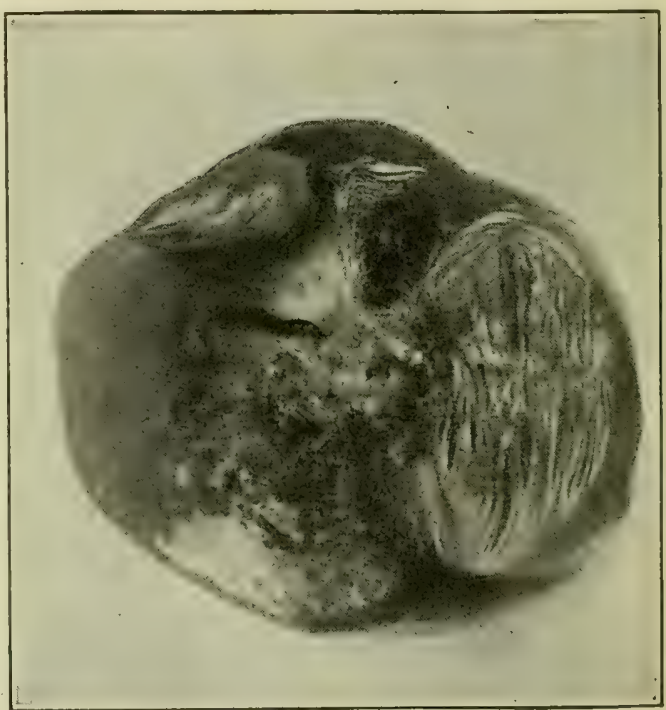

Frg. 18.-Downy mildew on tomato fruit. Medium late stage. spray. 
BLOSSOM-END ROT.

Blossom - end rot (fig. 20) is a diseased condition of the blos. som end of the fruit. It is most common in dry weather, especially after a period of rapid growth. The most successful method of overcoming it is to water the soil.

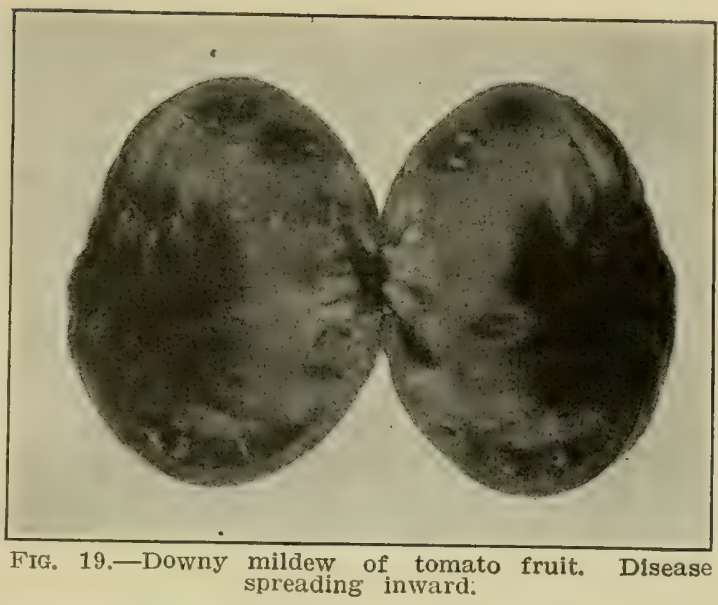

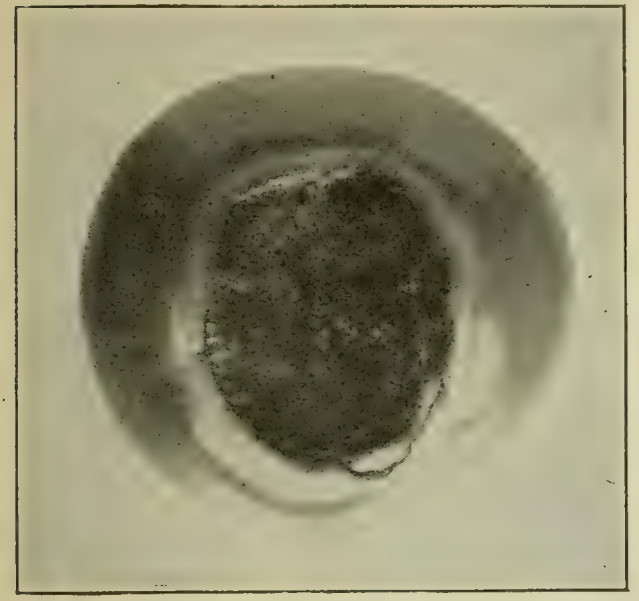

FIG. 20,-Blossom-end rot.
ANTHRACNOSE,

Anthracnose, or ripe rot (fig. 21), of tomato fruit is caused by a fungus which produces sunken spots with dark centers and watersoaked borders on the surface and soft areas in the interior. The only means of controlling it are preventive. Diseased fruits should be gathered and burned or buried so deeply that they will not be brought to the surface again.

SPRAYING TOMATOES.

Your decision as to whether or not you will spray your tomatoes will depend on the danger from leaf blights (early blight, southern tomato blight, leaf spot, and downy mildew), which are as a rule more prevalent in the upper districts. If you spray, get the proper equipment and do it thoroughly.

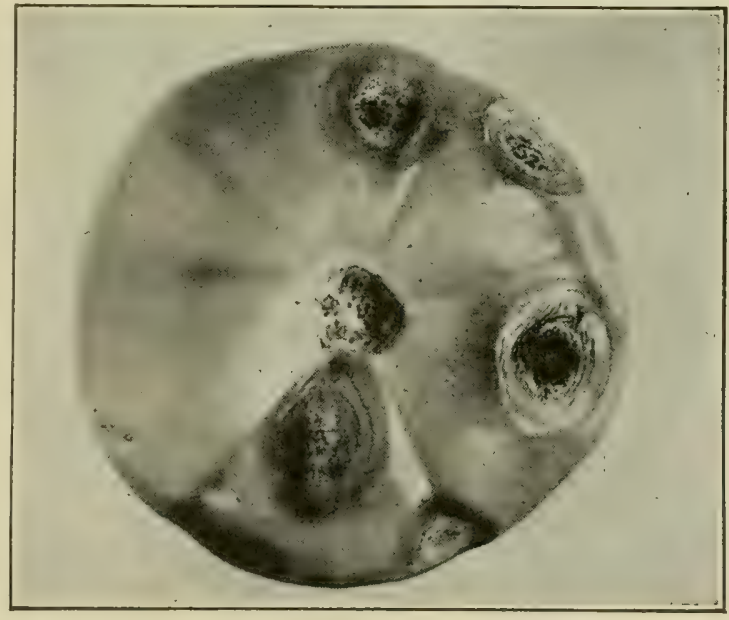

FIG. 21.-Anthracnose, or ripe rot. 
To get the best results, spraying: with Bordeaux mixture should be begun while the plants are young. Spray once about five days before transplanting, then again five days after transplanting, and repeat every ten days until the fruit is fully grown. A hard rain will frequently wash off the mixture and make it necessary to spray again. Five sprayings should be given during the season. Ten gallons of spray mixture will be necessary for each spraying. Five pounds of blue-stone and five pounds of fresh stone lime will be enough for the season. Secure these supplies at the beginning of the season. Have the blue-stone divided into five 1-pound lots. The entire quantity of lime may be slaked at the beginning by adrling water slowly until all the lumps are slaker. Keep this slaked lime in a bucket with a little water over it. Is long as it is covered with water it is good, but if it is exposed to the air it will dry out and become air-slaked. Lime which has been air-slaked can not be used in Bordeaux mixture.

Bordeaux mixture-How to make it for each spraying.

Copper sulphate (blue-stone).......................... 1

Quick lime (stone lime).............. pound, 1

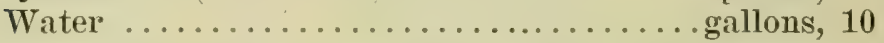

Blue-stone solution: Put 5 gallons of water in a wooden tub, tie the blue-stone in a coarse sack, and hang it in this water near the

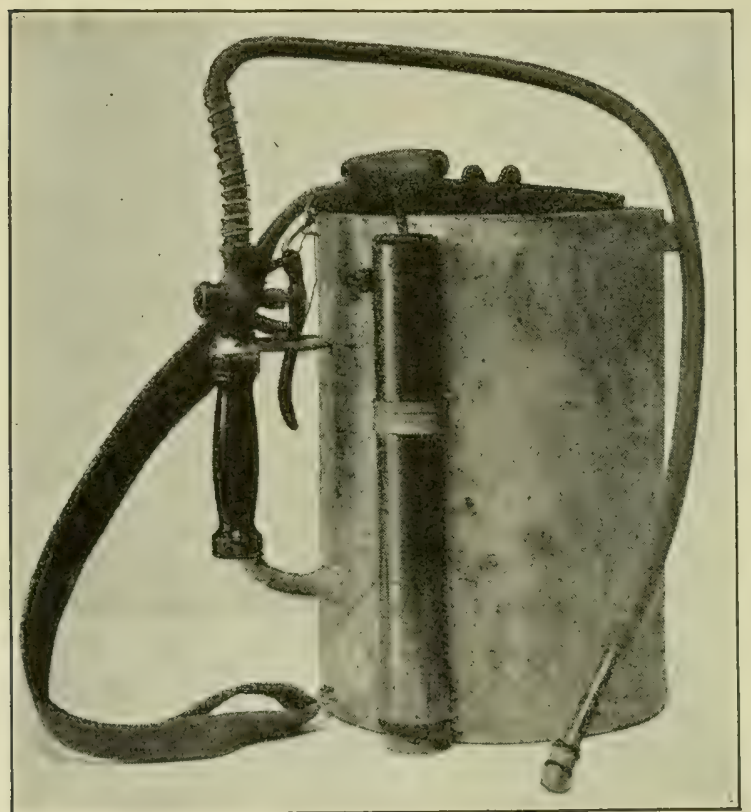

FIG. 22.-One of several kinds of compressed-air sprayers on the market. top. Do not use a metal vessel because the action of the blue-stone on the metal will ruin the vessel and make the solution worthless. Allow several hours for the blue-stone to dissolve. This will take place more quickly in hot water.

L i m e solution : Take one-fifth of the lime which has been slaked by water and $\operatorname{mix}$ it thoroughly in 5 gallons of water.

Mixing : Bordeaux mixture is made out of equal parts of these two solutions. It is important that they be carefully mixed, and that only as much of the mixturc be made as can be used at one spraying. Have the lime solution in one ressel and the copper sulphate solution in another. Have ready a third tub or other wooden ressel. Stir the solution well before using. Let two people 
pour the two solutions into the third vessel at the same time, stirring constantly to insure thorough mixing. Always stir the Bordeaux before putting it into the sprayer.

To be of value, spraying must be thoroughly done. The spray mixture must cover both the under and upper sides of the leaves.

For the tenth acre, a bucket spray pump -costing about $\$ 3$ or a knapsack sprayer costing about $\$ 5$ will be satisfactory. Compressedair sprayers (fig. 22), in which air pressure is developed by means of a pump and the liquid released when desired are a very effective type. Every farmer should have a small sprayer, as it can be used for many purposes and will more than pay for itself in one year. Wash the spray pump thoroughly after each using.

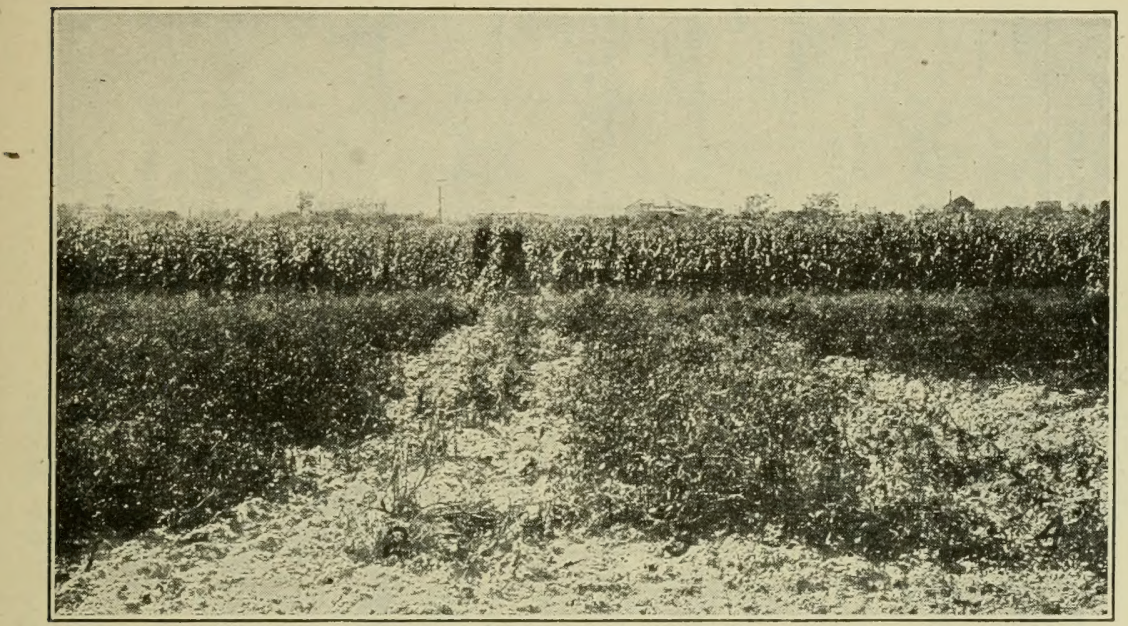

FIG. 23.-Rows 1 and 3 resistant varieties on wilt-infested land; rows 2 and 4 susceptible varieties killed by wilt.

\section{WILT-RESISTANT TOMATOES.}

If any part of your farm is infested with the wilt fungus, use wilt-resistant varieties, as they produce a good crop of fruit on wilt-infested land when other varieties die of the disease (fig. 23).

You will find on the next page a chart which gives the distinguishing characters of some of the more important diseases of the tomato and ways of preventing them.

Sincerely yours,

Ola Powell, Assistant in Home Demonstration Work. 


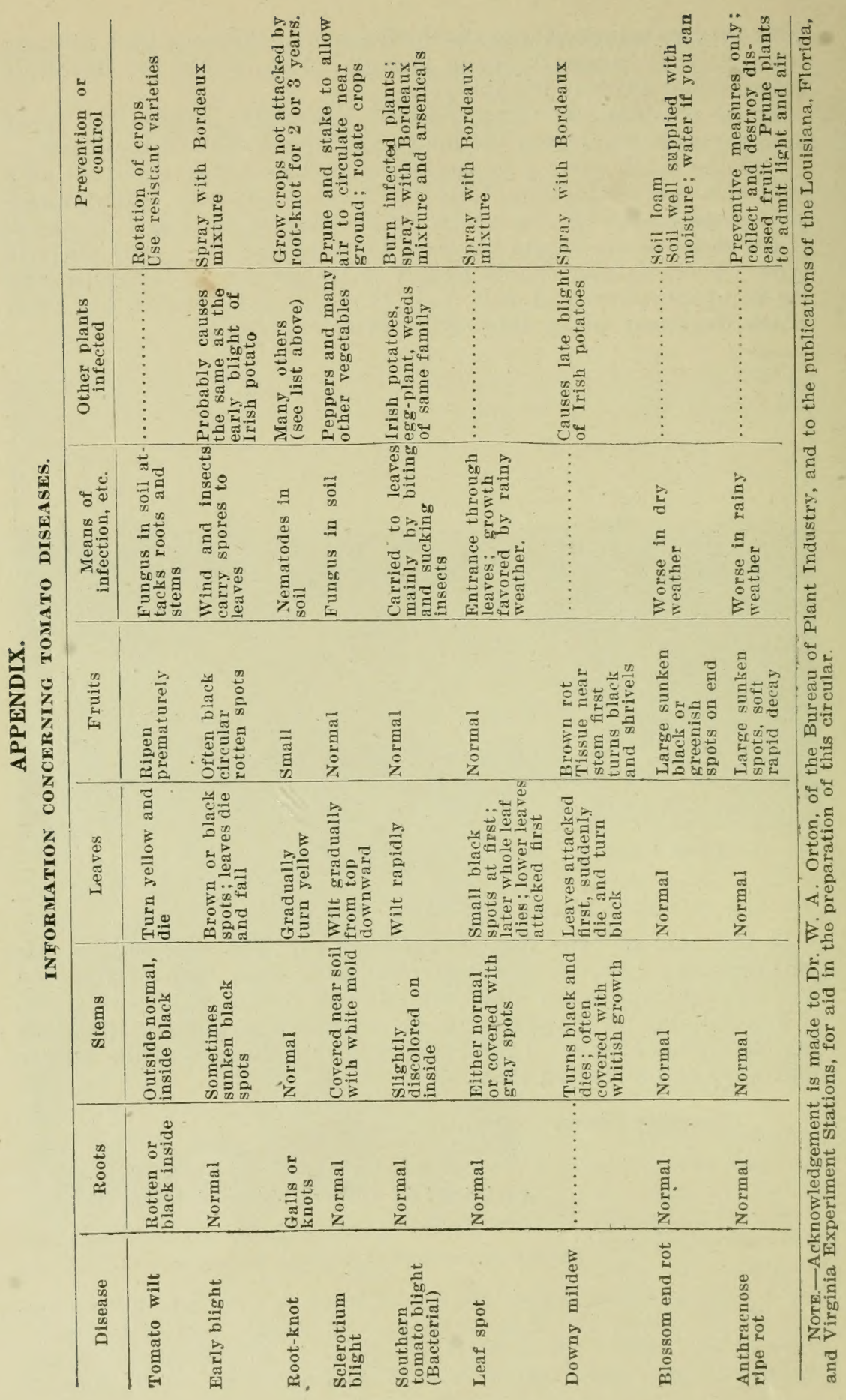





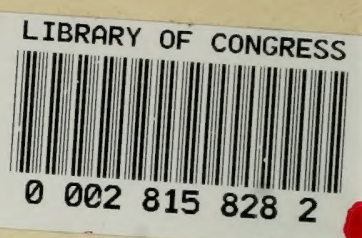

